\title{
Scope of Carbon Fibre-Reinforced Polymer Wheel Rims for Formula Student Racecars: A Finite Element Analytical approach
}

\author{
Sai Yashwanth Kandukuri ${ }^{1} \cdot$ Anand Pai $^{1}$ (D) $M$ Manikandan $^{1}$
}

Received: 23 August 2021 / Accepted: 9 January 2022/Published online: 7 February 2022

(C) The Author(s) 2022

\begin{abstract}
Wheel rims are vital components critical to the safety of an automobile. Conventional wheel rims have utilized monolithic materials like aluminium and magnesium alloys in replacement to heavier steel rims. To reduce the weight of the formula car, lightweight composite wheel rims with higher stiffness are explored in the current work. Composite wheel rims are still in their nascent stage for commercial automotive applications, although they are commonly seen more in motorsports. The factors like complex design, high cost, and difficulty in fabrication are some of the demerits of composite wheel rims. Formula Manipal racing has been building race cars for Formula India events for over 13 years, on which aluminium wheel rims were standardly fitted. In the current work, the design and finite element analysis of carbon fibre wheels rims were undertaken to replace the aluminium wheel rims after a thorough consideration of other potential materials also. The modelling was carried out on CATIA3DX ${ }^{\circledR}$, and finite element analysis was carried out using the ANSYS COMPOSITE PREP/POST (ACP) ${ }^{\circledR}$ module for laminate stackup and structural analysis tools for mechanical response. From the studies, the carbon fibre rims reduced the weight significantly by $42 \%$ while improving the factor of safety by $41 \%$ as compared to the current aluminium wheel rims while thermally outperforming magnesium and titanium alloys.
\end{abstract}

Anand Pai

anand.pai@manipal.edu

1 Department of Aeronautical and Automobile Engineering, Manipal Institute of Technology, Manipal Academy of Higher Education, Manipal 576104, India
Keywords Carbon fibre-reinforced polymer . Aluminium alloys · Magnesium alloys wheel rim · Finite element analysis - Factor of safety

\section{List of Symbols}

$\ddot{x}_{1} \quad$ Acceleration of unsprung mass $\left(\mathrm{m} / \mathrm{s}^{2}\right)$

$\ddot{x}_{2} \quad$ Acceleration of sprung mass $\left(\mathrm{m} / \mathrm{s}^{2}\right)$

$\dot{x}_{1} \quad$ Velocity of unsprung mass $(\mathrm{m} / \mathrm{s})$

$A_{y} \quad$ Lateral acceleration $\left(\mathrm{m} / \mathrm{s}^{2}\right)$

$A_{z} \quad$ Longitudinal acceleration $\left(\mathrm{m} / \mathrm{s}^{2}\right)$

$c_{1} \quad$ Damping constant

$F_{x} \quad$ Load acting normal to contact patch $(\mathrm{N})$

$F_{y} \quad$ Cornering force $(\mathrm{N})$

$F_{z} \quad$ Longitudinal load $(\mathrm{N})$

$h \quad$ Height of centre of gravity above ground level (m)

$k_{1} \quad$ Spring constant for unsprung mass

$l \quad$ Wheel base of the car (m)

$m_{1} \quad$ Unsprung mass $(\mathrm{kg})$

$m_{2} \quad$ Sprung mass $(\mathrm{kg})$

$t \quad$ Track width (m)

$W \quad$ Laden weight of the car $(\mathrm{N})$

\section{Introduction}

The automotive industry has seen a steady evolution of novel materials for the various aggregates and sub-systems, to reduce the manufacturing costs and improve the fuel economy. The conventional materials-steel and aluminiumhave long since crossed the threshold of innovation; the advantages they offered in terms of strength, formability, toughness, impact resistance and resilience are challenged by the high strength fibre-polymer composites. Carbon 
fibres are lightweight, have high strength and modulus, withstand high temperatures and fatigue, are corrosion resistant. Dispersed in a matrix of epoxy, the carbon fibrereinforced composite (CFRP) serves as a potential replacement for conventional materials. However, carbon fiber composites are expensive, the fabrication is difficult for intricate and complex parts. Hence, their current use is restricted to the niche segment of automobiles like luxury and sports cars [1]. The common areas of application include the body panels (both interior and exterior), structures of the performance parts, passenger cell components, diffusers and roofings. Recent research has shown the extension of CFRPs in dynamic components like wheel rims and axle shafts, to bank on the excellent fatigue resistance of carbon fibre [2].

Wheel rims serve as a platform for mounting the tyres, and they transmit the torque from the axle to the tyres $[3,4]$. Wheel rim experiences different types of loading like radial, torsional and bending. Since the wheel rims are in direct contact with the road through the tyre, they are considered as an un-sprung mass. Hence, the weight of the rims plays an essential role in the dynamics of the car [5-8]. Reduction in weight of the wheel rim results in better control of its movement and allows the springs/dampers to facilitate appropriate tyre-road contact. This ensures improved grip and cornering at high speeds. Since the grip is a significant factor for formula student cars (Fig. 1) directly influencing the car's lap times, weight reduction by employing carbon fibre was taken up, to the magnitude of around $1 \mathrm{~kg}$ per wheel rim, an overall reduction of $4 \mathrm{~kg}$ for the car weighing $200 \mathrm{~kg}, 2 \%$. Weight also plays a role in the inertia of rotation. For a rotating body, reducing weight implies it requires less torque to rotate and requires less force for acceleration or braking, resulting in better handling of the car.

Pure aluminium being soft has limited applications in the industry. By adding impurities, alloying and

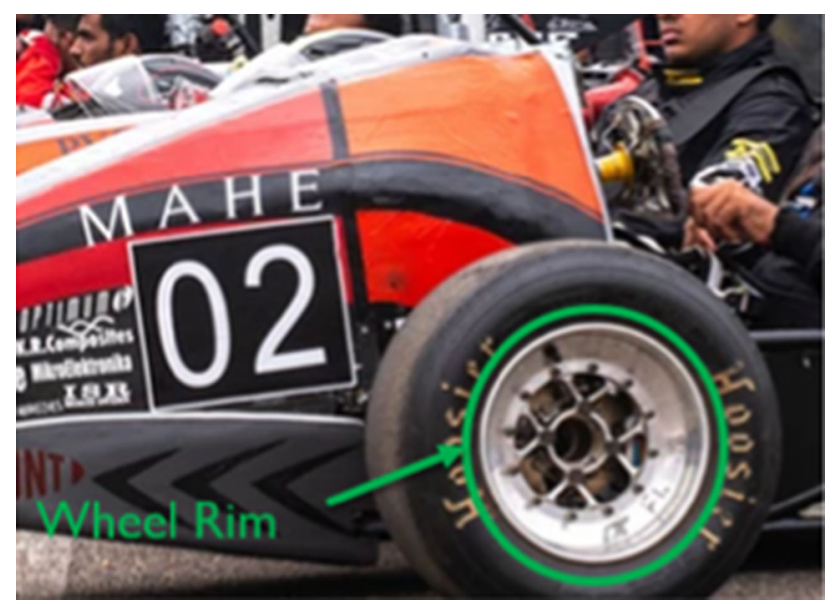

Fig. 1 Photograph of a Formula Student Car Wheel appropriate heat treatment, the mechanical properties were improved. This helped meet the operational requirements of the various applications. Aluminium alloys being lightweight (one-third the density of steel), and corrosion resistant, found use as rim materials in most automobiles. However, possessing a very high coefficient of thermal expansion hindered applications of aluminium alloy wheel rims at temperatures above $600{ }^{\circ} \mathrm{C}$ [9]. Magnesium is a highly flammable material though it requires high activation energy for self-ignition. To control the flammability, alloying of magnesium offered an excellent material for wheel rims, commonly seen in sports cars, bikes and highperformance vehicles [10]. Magnesium alloys being 30\% lighter than aluminium alloys are advantageous for components that run at high speeds and must be light in weight, to reduce inertial forces [9]. Titanium alloys have very high tensile strength and toughness properties at average and extreme temperatures than aluminium or magnesium alloys. They show excellent corrosion resistance properties, but are heavier than other alloys mentioned affecting the rim mass. They deliver excellent mechanical properties; even at higher temperatures. The main disadvantages are that titanium is an expensive material, and it is tough to machine titanium alloys and required specialist processes for material removal [11].

Recent research has seen use of different alternate materials used for wheel rim construction (Fig. 2). Shinde et al. [13] carried out a study on the failure of Formula car wheel hubs made of AA6061-T6 with surface treatment comprising Anodizing to a depth of $25 \mu \mathrm{m}$. The authors found that the crack development due to the presence of bending, torsional shear and axial stresses led to the failure of the wheel hub. Chowdhary et al. [2] compared alloy steel and wrought magnesium alloy ZK60A (high strength and ductility) wheel rims using finite element analysis. It was found that the stress levels generated in the steel rim were four times that of the magnesium alloy rim. Curb
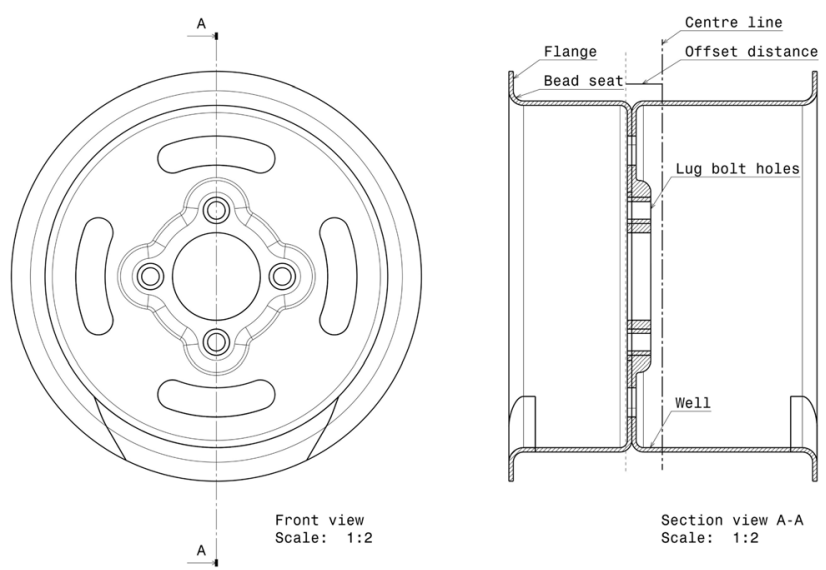

Fig. 2 Rim construction and nomenclature [12] 
weight and mileage of eight vehicles from different manufacturers were compared. It was deduced that every $90 \mathrm{~kg}$ of weight reduction increases the mileage by unit of one. Krishna et al. [9] investigated the effect of the geometrical features of the wheel rims-elliptical and hexagon spokes on the performance. Finite element analysis was performed by considering three materials-Aluminium alloy, magnesium alloy and CFRPs. Key metrics considered for the study were von Mises stress, deformation and shear stress. Among the three materials, the CFRP rim showed significantly less deformation compared to the other two metallic alloys for both types of spokes, with lower von Mises stress for the hexagonal spokes as compared to elliptical spoke geometry. However, the authors have not considered the effect of the remote forces at the contact patch like cornering force, acceleration/deceleration forces, and the clamping force due to fasteners on the wheel rim. Bhagwat [14] investigated different designs of CFRP wheel rims for Formula Society of Automotive Engineers (FSAE) vehicle, arriving at the lightest design weighing $18 \%$ lesser than aluminium wheel rims. The limitation of this work was the low Inverse Reverse Factor (IRF) of 0.9 for the spokes, which could be compensated at the expense of the wheel hub, which was found to have excessive thickness.

Table 1 Properties of different materials considered for the wheel rim [14]

\begin{tabular}{llll}
\hline Properties & $\begin{array}{l}\text { Aluminium } \\
\text { alloy } \\
\text { AA7075 }\end{array}$ & $\begin{array}{l}\text { Magnesium } \\
\text { alloy RZ5 }\end{array}$ & $\begin{array}{l}\text { Titanium } \\
\text { alloy 6Al- } \\
4 \mathrm{~V}\end{array}$ \\
\hline $\begin{array}{l}\text { Density }\left(\mathrm{kg} / \mathrm{m}^{3}\right) \\
\begin{array}{l}\text { Ultimate tensile } \\
\text { strength }(\mathrm{MPa})\end{array}\end{array}$ & 2810 & 1840 & 4430 \\
$\begin{array}{l}\text { Tensile modulus }(\mathrm{GPa}) \\
\text { Shear strength }(\mathrm{MPa})\end{array}$ & 71 & 226 & 1030 \\
$\begin{array}{l}\text { Thermal conductivity } \\
(\mathrm{W} / \mathrm{mK})\end{array}$ & 130 & 44 & 95 \\
$\begin{array}{l}\text { Specific heat }(\mathrm{kJ} / \mathrm{kgK}) \\
\text { Coefficient of thermal } \\
\text { expansion }\left(\times 10^{-6 /}\right.\end{array}$ & 2.5 & 138 & 520 \\
$\quad$ K) & & 61 & 6.7 \\
\hline
\end{tabular}

Table 2 Description of CFRP stackups for wheel rim parts

\begin{tabular}{lllc}
\hline Stackup & Part of the rim & $\begin{array}{l}\text { Number of } \\
\text { lamina }\end{array}$ & CFRP Ply stackup \\
\hline Bottom & Well, Beads and & 5 & $45^{\circ} \mathrm{BD} / 0^{\circ} \mathrm{BD} / 45^{\circ} \mathrm{BD} /$ \\
stackup & wheel hub & & $0^{\circ} \mathrm{UD} / 45^{\circ} \mathrm{UD}$ \\
Centre & Beads & 4 & $0^{\circ} \mathrm{BD} / 0^{\circ} \mathrm{BD} / 0^{\circ} \mathrm{BD} /$ \\
stackup & & & $0^{\circ} \mathrm{BD}$ \\
Top & Well, Beads and & 5 & $45^{\circ} \mathrm{BD} / 0^{\circ} \mathrm{BD} / 45^{\circ} \mathrm{BD} /$ \\
stackup & wheel hub & & $0^{\circ} \mathrm{UD} / 45^{\circ} \mathrm{UD}$ \\
\hline
\end{tabular}

Lowering the IRF will, in turn, increase the Factor of safety. High factor of safety from finite element analysis results was necessary to account for the assumptions of steady-state and static conditions during the analysis, while in actual operation, transient state and dynamic conditions exist. Ressa [15] employed pneumatics to create an experimental test setup for wheel rims. By Placing three pneumatic cylinders at suitable locations for applying the forces on the wheel rim-normal force, cornering force, acceleration and deceleration forces. The author also discussed the issue faced during lay-up, mainly the draping problems in circular and fillet areas, which could be

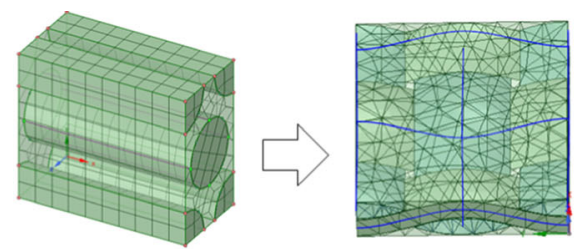

Micro FE model of UD-RVE Micro FE model of BD-RVE

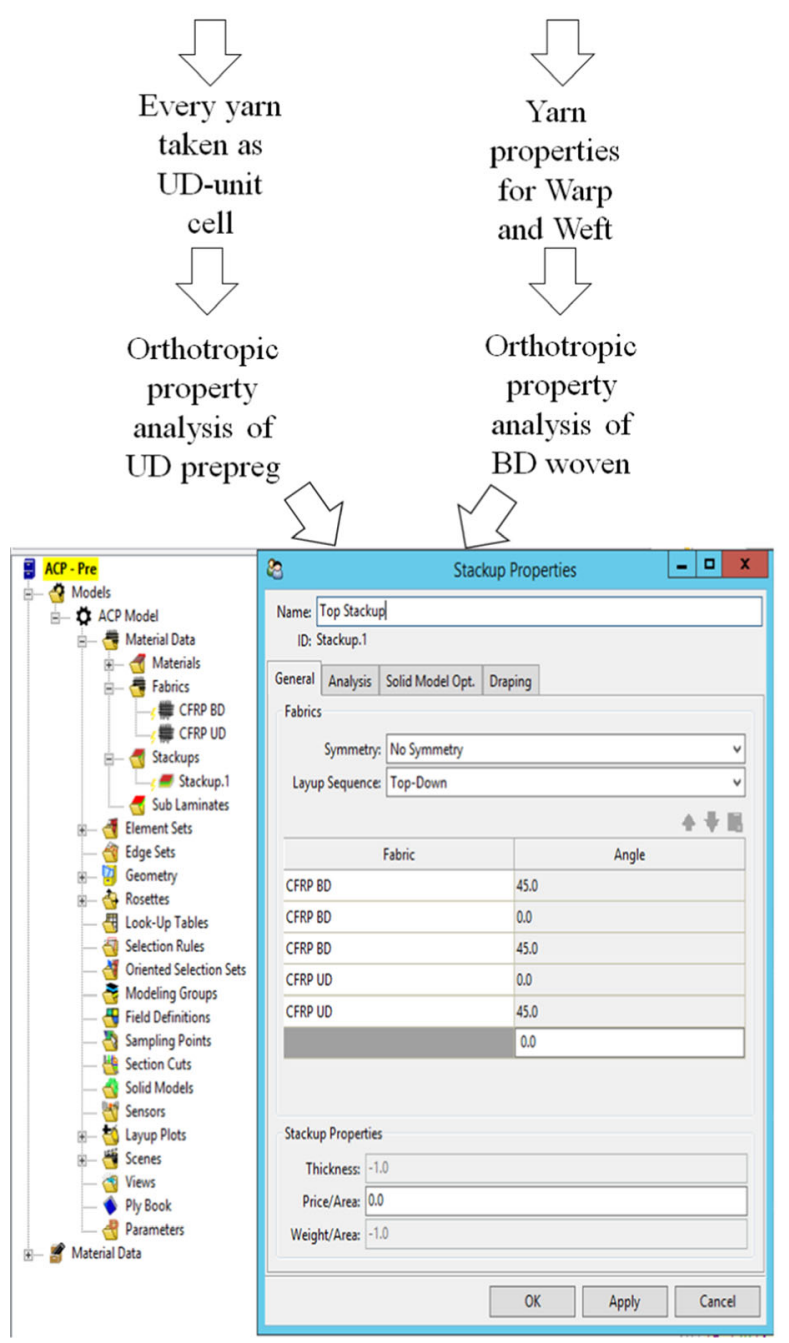

Fig. 3 RVE approach to determining the orthotropic properties of CFRP prepregs 
Table 3 Properties of CFRP UD and BD prepregs (for $0^{\circ}$ orientation with global $x$-axis)

\begin{tabular}{lll}
\hline Properties & CFRP-UD ply & CFRP-BD ply \\
\hline Density $\left(\mathrm{kg} / \mathrm{m}^{3}\right)$ & 1490 & 1420 \\
Coefficient of thermal expansion, $\alpha_{x}\left(\times 10^{-6} /{ }^{\circ} \mathrm{C}\right)$ & -0.47 & 2.2 \\
Coefficient of thermal expansion, $\alpha_{y}\left(\times 10^{-6} /{ }^{\circ} \mathrm{C}\right)$ & 30 & 2.2 \\
Coefficient of thermal expansion, $\alpha_{z}\left(\times 10^{-6} /{ }^{\circ} \mathrm{C}\right)$ & 30 & 10 \\
Modulus of elasticity, $E_{x}(\mathrm{GPa})$ & 121 & 61.3 \\
Modulus of elasticity, $E_{y}(\mathrm{GPa})$ & 8.6 & 61.3 \\
Modulus of elasticity, $E_{z}(\mathrm{GPa})$ & 8.6 & 6.9 \\
Poisson's ratio, $v_{x y}$ & 0.27 & 0.04 \\
Poisson's ratio, $v_{y z}$ & 0.4 & 0.3 \\
Poisson's ratio, $v_{z x}$ & 0.27 & 0.3 \\
Shear modulus, $G_{x y}(\mathrm{GPa})$ & 4.7 & 3.3 \\
Shear modulus, $G_{y z}(\mathrm{GPa})$ & 3.1 & 2.7 \\
Shear modulus, $G_{z x}(\mathrm{GPa})$ & 4.7 & 2.7 \\
\hline
\end{tabular}

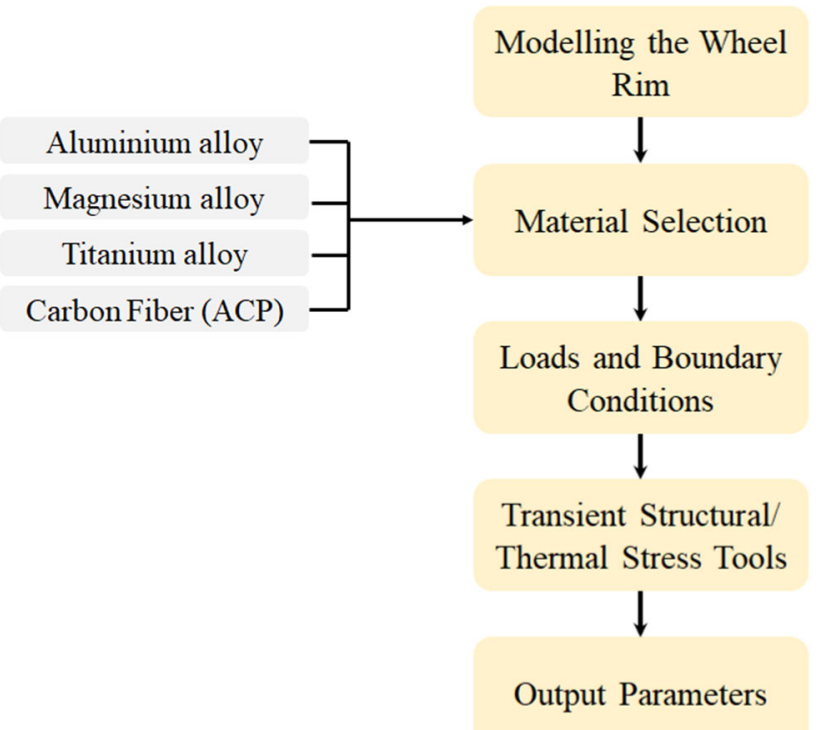

Fig. 4 Finite element model of wheel rim with boundary conditions. a Thermal analysis, b transient structural analysis

minimized by creating slits and overlapping. Also, the mould release issues were discussed. Salunkhe et al. [16] compared wheel rims made of aluminium and magnesium alloys (ZA21). For ZA21, the equivalent stress was 20.7 $\mathrm{MPa}$, and the maximum deformation was $0.054 \mathrm{~mm}$, which was better than that of the aluminium wheel rims. The magnesium alloy wheel rims could be alloyed with zinc to improve the strength, fatigue life (endurance limit), reliability, and overall weight and cost. Walther et al. [17] introduced a testing technique to measure temperature on CFRP wheel rim surfaces, using temperature indicating strips near critical areas like the brake disc area. The CFRP wheel rim was finished by machining (milling by diamond-

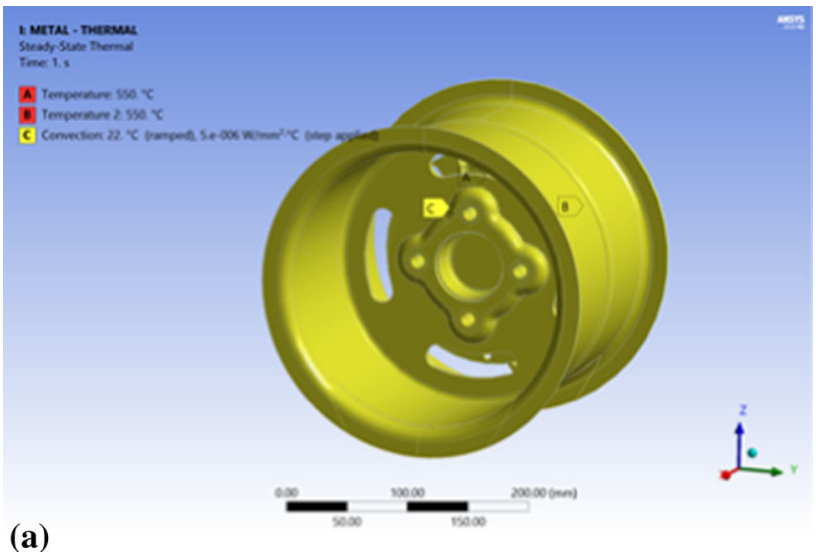

(a)

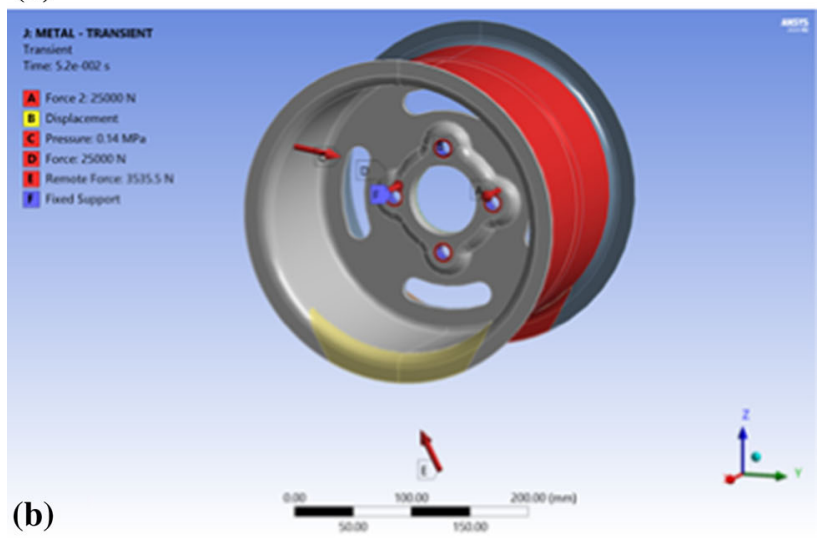

Fig. 5 Steps in the structural analysis of wheel rims

coated tools) near the flange and the bead seat area for perfect seating of the tyre in the rim groove and preventing air leakage. Chapman et al. [12] opine that a car's tyre must constantly contact the ground and exert a significant amount of (normal) force to remain controllable. Accordingly, the car's suspension system must follow the road and 
Table 4 Specifications of the race car wheel rim

\begin{tabular}{ll}
\hline Parameter & Dimensions $(\mathrm{mm})$ \\
\hline Rim diameter & 280 \\
Offset distance & 24.25 \\
lug bolt hole diameter & 12 \\
Wheel hub diameter & 135
\end{tabular}

Table 5 Boundary conditions for the wheel rim FEA

\begin{tabular}{ll}
\hline Type of load & Value \\
\hline$F_{x}(\mathrm{~N})$ & 2500 \\
$F_{y}(\mathrm{~N})$ & 1500 \\
$F_{z}(\mathrm{~N})$ & 2000 \\
Air pressure $(\mathrm{kPa})$ & 140 \\
Clamping force $(\mathrm{N})$ & 25,000 \\
Surface temperature $\left({ }^{\circ} \mathrm{C}\right)$ & 550 \\
\hline
\end{tabular}

Table 6 FE mesh details of CFRP wheel rim

\begin{tabular}{llll}
\hline Element type & Element quality & Aspect ratio & Skewness \\
\hline Automatic & 0.858 & 1.273 & 0.143 \\
Multizone & 0.775 & 1.474 & 0.213 \\
All triangles & 0.885 & 1.269 & 0.118 \\
\hline
\end{tabular}

Table 7 FE mesh details of $\mathrm{Al}, \mathrm{Mg}$ and $\mathrm{Ti}$ alloy wheel rims

\begin{tabular}{llll}
\hline Element type & Element quality & Aspect ratio & Skewness \\
\hline Automatic & 0.803 & 1.95 & 0.276 \\
Multizone & 0.807 & 2.571 & 0.277 \\
All triangles & 0.808 & 1.963 & 0.279 \\
\hline
\end{tabular}

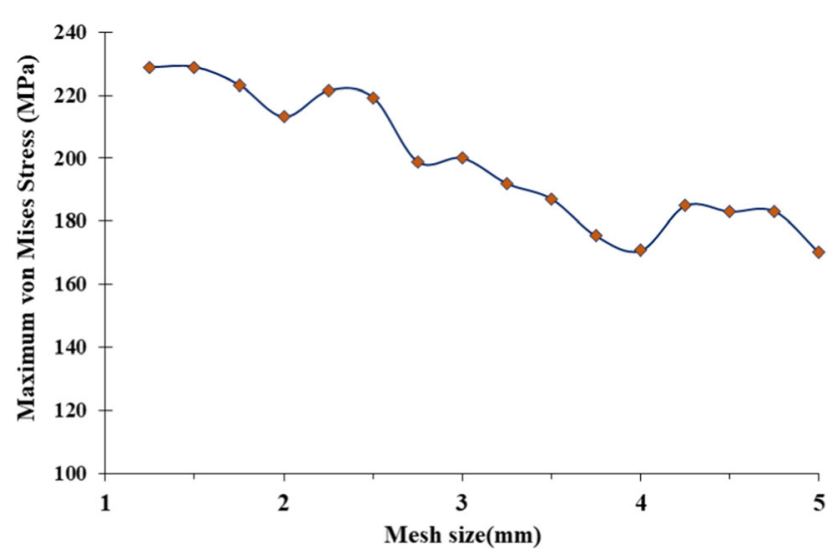

Fig. 6 Grid independency check for wheel rim model all its imperfections. The undamped natural frequency of the suspension response time could be used to describe it.

$\ddot{x_{1}}=\frac{-k_{1} x_{1}}{m_{1}}=\frac{-m_{2} \ddot{x}_{2}}{m_{1}}=\frac{2 c_{1} \dot{x_{1}}}{m_{1}}$

For a two-degree of freedom system with spring and mass, Eq. 1 shows that a decrease in $m_{1}$ results in an increase in the acceleration and thus a better response for the car. It is possible to boost the sprung mass to raise the mass ratio but Newton's second law predicts a decrease in the car's acceleration and increase in the racing situation car's lap times. The best approach was to reduce the vehicle's unsprung mass by employing lighter materials for the parts of the car.

\section{Materials and Methods}

\section{Materials for the Wheel Rims}

The monolithic and isotropic materials considered for the wheel rims are Aluminium alloy AA7075, Magnesium alloy RZ5 and Titanium alloy Ti-6Al-4V. Carbon fibrereinforced epoxy was the target material (orthotropic) taken up as a lightweight and viable replacement for the conventional materials. The mechanical properties of the monolithic materials are shown in Table 1. The CFRP prepregs considered in the study contain $55 \%$ carbon fibre by volume in epoxy matrix. Two types of CFRP prepregscarbon fibre epoxy UD (uni-directional) and carbon fibre epoxy BD (bi-directional woven)-were used for building the stackups, layup details are given in Table 2, and the selection of the CFRP plies was based on recent wheel rim ply stackups in $[14,17]$. Since CFRP prepregs display orthotropic behaviour [18], the material properties for the UD and BD prepregs have been evaluated by the Representative Volume Element (RVE) approach, and using Material Designer Tool of ANSYS R20.0 ${ }^{\circledR}$, the process is shown in Fig. 3. The thermo-mechanical properties of the CFRP prepregs are given in Table 3. These properties were considered in the ACP module (shown in Fig. 3) for the different plies in the stackups pertaining to the corresponding parts of the CFRP wheel rim.

\section{Modelling and Design of Wheel Rims}

The wheel rim design needed vital inputs related to the magnitude and types of loads exerted on the wheel rim due to the tyres, during regular operation of the formula car. The rim construction and its parts are shown in Fig. 4. The modelling was carried out using the CATIA $3 \mathrm{DX}^{\circledR}$ software. The loads and boundary conditions recorded on the standard aluminium rims on the formula car were utilized 


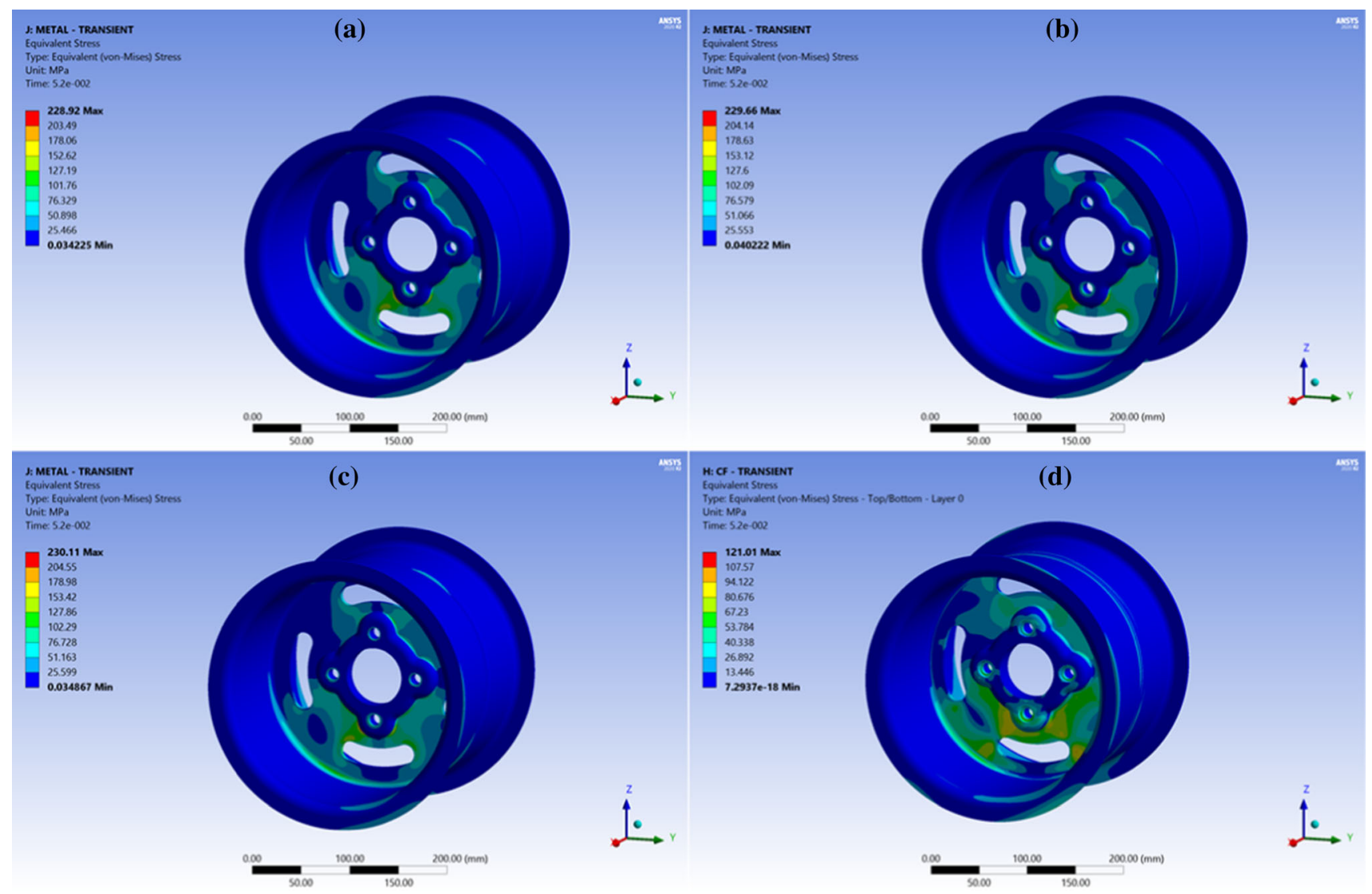

Fig. 7 von Mises Stress for different wheel rim materials. a Aluminium, b magnesium, c titanium, d CFRP

for the FEA of the CFRP rims as shown in Fig. 5. The model of the CFRP wheel rim was kept similar to the aluminium rims in terms of the specifications given in Table 4. For the finite element analysis, the following assumptions were made-

- The monolithic materials-Al, Mg and Ti-were considered to be isotropic and homogeneous, while for CFRP, orthotropic material properties were considered.

- For the alloy wheel construction, at the connection interface, bonded condition was allocated as there is no relative motion between the two parts.

- The time step for the transient analysis was computed based on the top speed of the car.

- For the thermal analysis, convection was considered for the wheel rim with quiescent air, and air velocity was taken as zero.

- During the FE analysis, the orientation of the wheel centre was considered in upright position.

Two significant parts of the wheel rim are the front and rear components. Rim contained a foam core material with aluminium dowels mounted near the wheel hub area. The aluminium tubes were placed near the mounting points to improve the stiffness and withstand tightening torque caused by the bolts. For monolithic materials- aluminium, magnesium and titanium, the material properties were directly allocated in the structural modules to the 3D wheel rim geometry. But, the CFRP material stackup was developed on the ACP module of ANSYS R20.0 workbench and exported as shell data into the geometry which required a planar mesh. The thermal response of the wheel rims is vital to check whether any overheating is occurring due to close proximity with the brake disc. In composite wheel rims, the polymer matrix glass transition temperature limits the maximum allowable temperature for the wheel rims. To obtain the operating temperatures on the wheel rims, temperature sensors were fitted on the current aluminium wheel rims, and the maximum temperatures were noted and used for the FEA. It was found that the loads acting at the contact patch of the wheel were the most critical to the performance of the wheel rims. The dynamic loads experienced by the wheel rims are complex owing to the split-second transfer of loads from the tyre-road contact patch to the wheel rims. Three main loads were found to act near the contact patch in three mutually orthogonal directions [19],

- Normal load $\left(F_{x}\right)$, the load is acting normal to the contact patch generated directly due to the car's weight Eq. 2 


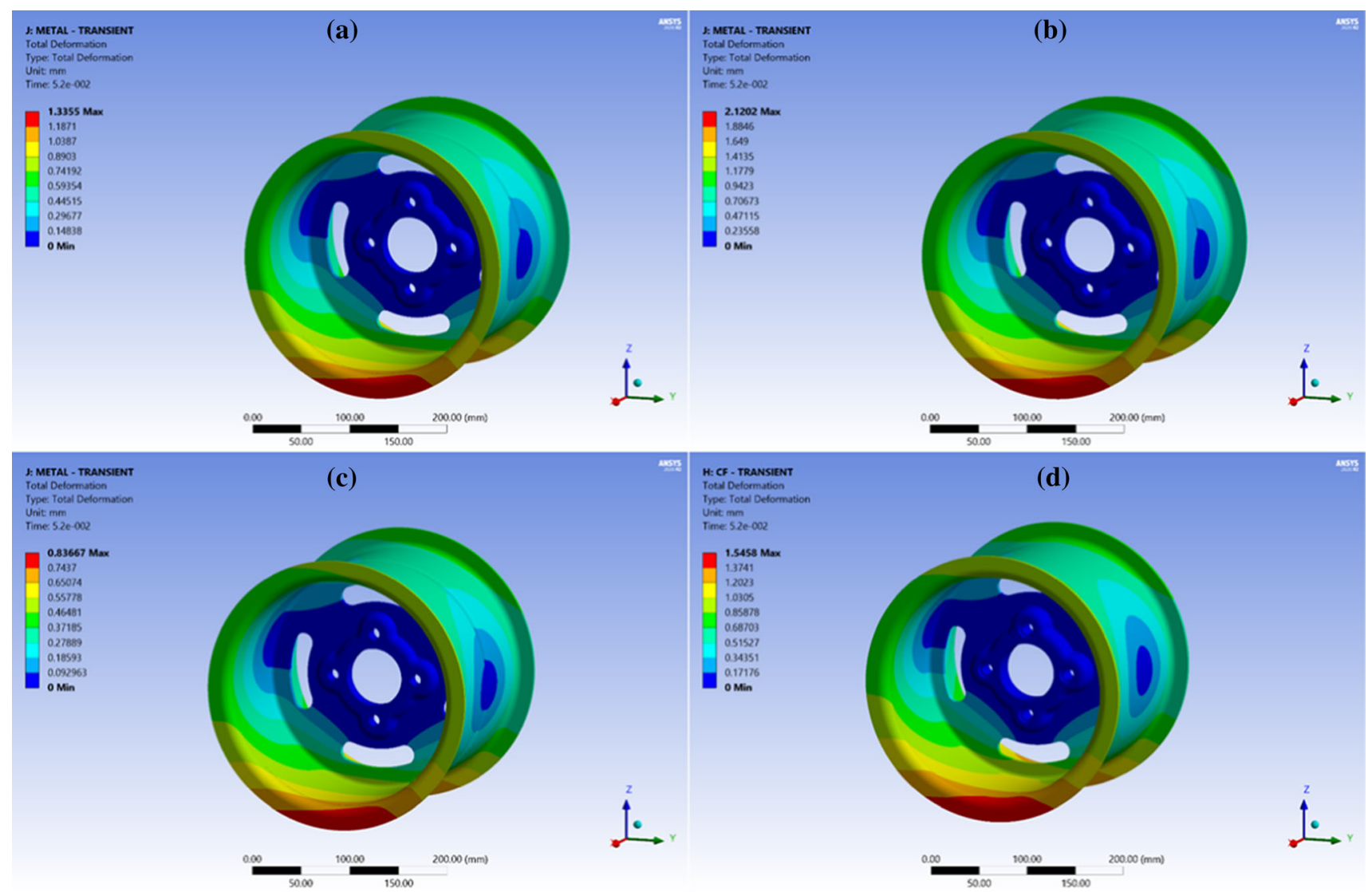

Fig. 8 Deformation (in $\mathrm{mm}$ ) for different wheel rim materials. a aluminium, b magnesium, $\mathbf{c}$ titanium, $\mathbf{d}$ CFRP

- Lateral load $\left(F_{y}\right)$, the load acting to the side of the contact patch due to the cornering of the car Eq.3

- Longitudinal load $\left(F_{z}\right)$, the load acting to the front of the contact patch (into the plane) due to acceleration or braking Eq. 4

$$
\begin{aligned}
& F_{x}=\frac{W}{4} \\
& F_{y}=\frac{A_{y} h}{t} \\
& F_{z}=\frac{A_{z} h W}{l}
\end{aligned}
$$

Apart from the contact patch loads, the air pressure acting on the inner wall of the wheel rims also has to be considered. For the standard FM20 wheels, the inflation pressure of the tyre is $14-20 \mathrm{psi}(97-135 \mathrm{kPa})$ which was applied on the inner wall of the wheel rim. Wheels are bolted to the upright with pre-defined tightening torque. The clamping force was assigned as another boundary condition, applied on either side of the wheel hub with the same magnitude but opposite direction to create a clamping effect [20]. The rear surface of the wheel hub is in contact with the wheel centre and is not displaced in any direction
[21]. Hence, this surface was constrained. Table 5 shows the boundary conditions for the wheel rims. The finite element analysis was carried out using the Transient Structural Tool and Thermal Stress Tools of ANSYS R20.0 ${ }^{\circledR}$. The key parameters considered for the FE analysis are IRF/safety factor, Total deformation, Von Mises stress and temperature. The flowchart for the finite element analysis is shown in Fig. 5.

The mesh details for the CFRP wheel rim model are provided in Table 6 while that for the metallic alloys- $\mathrm{Al}$, $\mathrm{Mg}$ and $\mathrm{Ti}$ are given in Table 7.

\section{Grid Independency Study}

Mesh sensitivity analysis was performed by considering "Maximum von Mises stress" from the transient structural analysis as a parameter. The mappable faces of the wheel rim were chosen for face meshing using quad elements. Asymmetric, non-circular or cylindrical faces with some pockets were meshed with tetrahedral elements. The initial mesh size selected was $5 \mathrm{~mm}$, and the size was reduced in the decrements of $0.25 \mathrm{~mm}$. Stress values for different mesh sizes were plotted as shown in Fig. 6. The stress values remained constant at a mesh size of $1.5 \mathrm{~mm}$ which 


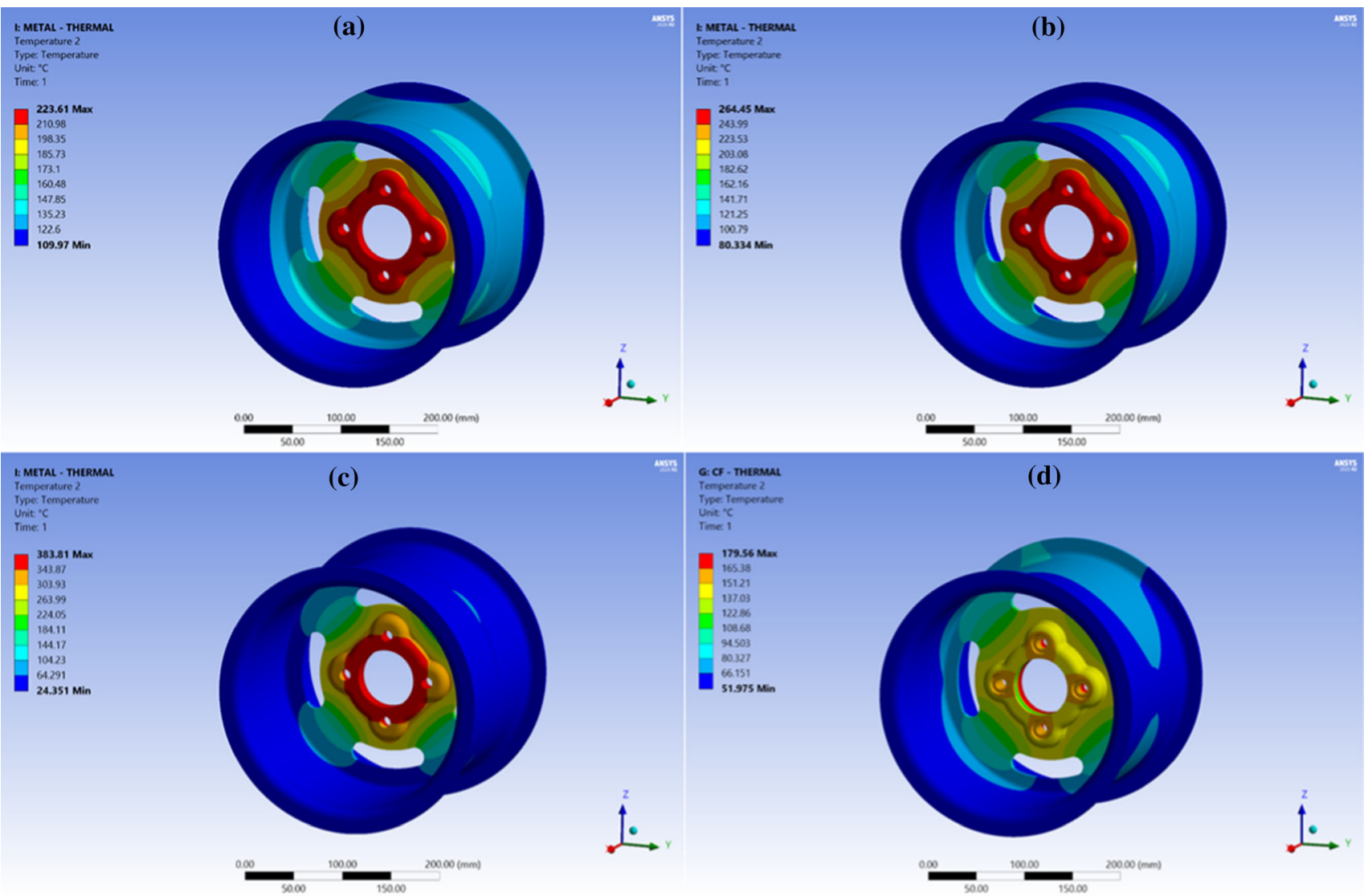

Fig. 9 Temperature contour for different wheel rim material. a aluminium, b magnesium, $\mathbf{c}$ titanium, $\mathbf{d}$ CFRP

Table 8 Comparison of FEA results of different wheel rim materials

\begin{tabular}{|c|c|c|c|c|}
\hline Metric & Aluminium & Magnesium & Titanium & CFRP \\
\hline Maximum von Mises stress (MPa) & 228.9 & 229.7 & 230.1 & 121.0 \\
\hline Maximum deformation (mm) & 1.336 & 2.120 & 0.837 & 1.546 \\
\hline Factor of safety & 2.079 & 0.570 & 3.824 & 2.981 \\
\hline Surface temperature $\left({ }^{\circ} \mathrm{C}\right)$ & 223.6 & 264.5 & 383.8 & 179.6 \\
\hline Mass (kg) & 2.21 & 1.42 & 3.69 & 1.28 \\
\hline
\end{tabular}
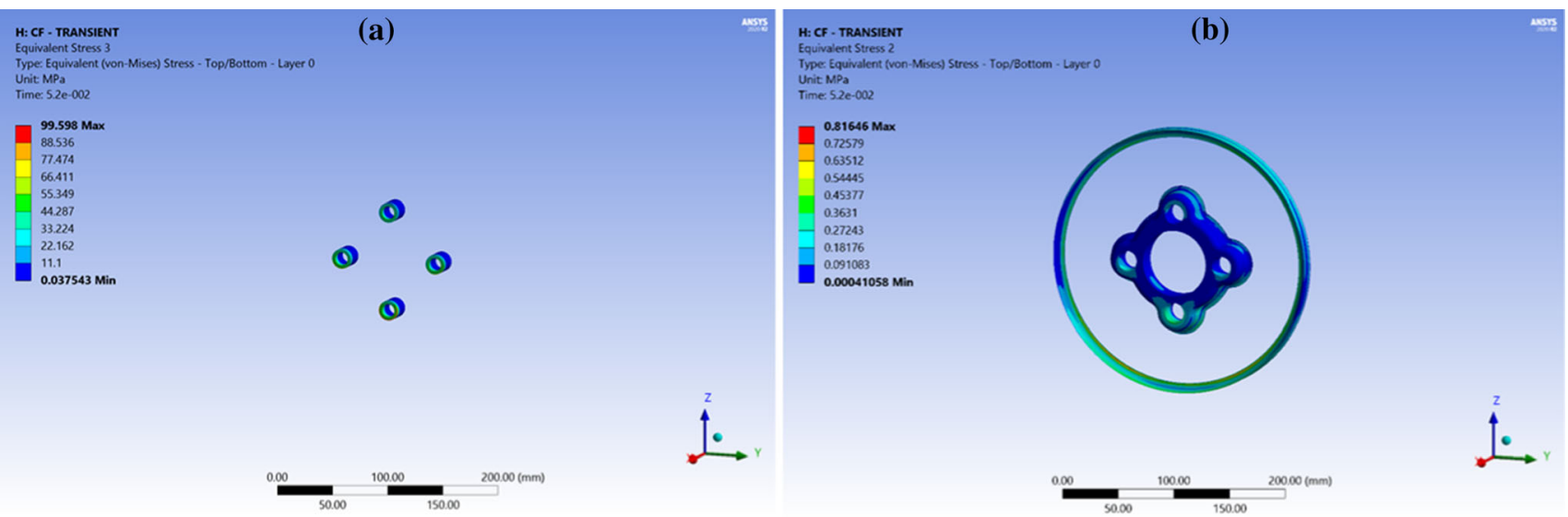

Fig. 10 von Mises stress distribution for CFRP rim at a Core b Dowel 
was selected as the common mesh size for all the four materials for the wheel rim considered in the study.

\section{Results and Discussion}

The four materials considered for the wheel rim were evaluated based on the key metrics-Maximum deformation, von Mises stress, safety factor and maximum temperature. As shown in Fig. 7, for aluminium, the maximum stress of 228.9 MPa was observed near one of the mounting points, owing to the existence of a sharp edge contributing to the stress concentration. The stresses induced are lower than the yield strength of aluminium, while magnesium and titanium displayed marginally higher maximum von Mises stress values compared to that of aluminium. But, in the case of the CFRP wheel rim, the maximum stress value was 121.0 MPa which was lowest among the four materials, and also within the strength limits of the composite.

The resultant force due to the contact patch (comprising Normal, Lateral and Longitudinal)led to a slight twist in the Rim with respect to the wheel hub. The 'Well' area was deforming under load with respect to the vertical surface, resulting in higher stress values near the edge. Maximum deformation for aluminium wheel rim of $1.335 \mathrm{~mm}$ (Fig. 8) was observed at the bottom portion, coinciding with the point of action of the remote force. For magnesium wheel rim, the maximum deformation was $2.120 \mathrm{~mm}$ higher than aluminium, while titanium wheel rims showed a deformation of $0.837 \mathrm{~mm}$ which was the lowest among the all the rim materials. For CFRP wheel rims, the second highest maximum deformation of $1.546 \mathrm{~mm}$ was noticed. At the edges, the carbon fibre did not reinforce the Well and vertical portion edge. To make up for the foam material used to fill the edges caused by the carbon fibre draping, additional layers were applied on the 'Well' area, joining both the parts to take up tensile loads caused due to bending, but a significant reduction was not observed due to the twist produced in the Rim. Additional layers were added in the rim 'Bead', resulting in a slight reduction in the deformation.

A maximum temperature of $223.6^{\circ} \mathrm{C}$ was observed at the centre section of the aluminium rim as shown in Fig. 9. Brakes assembly mounting was located at the rear of the Rim, one side of the assembly being the wheel centre entirely enclosed by the rim, and the other side, the suspension assembly was tightly packed allowing minimum air to circulate. Slots provided in the vertical portion allow air to circulate and keep the brake disc and caliper in contact with the moving air, allowing convective heat transfer. For magnesium wheel rim, the maximum temperature was $264.5^{\circ} \mathrm{C}$, while that for the Ti wheel rim was $383.8^{\circ} \mathrm{C}$. For CFRP wheel rims, the least value of the peak temperature of $179.6{ }^{\circ} \mathrm{C}$ was observed which was less than the Glass transition temperature of the epoxy binder [18]. Table 8 compares the FE results for all the rim materials. CFRP wheel rims show the second best safety factor next to titanium, lowest maximum temperature and maximum von Mises stress, second highest maximum deformation.

Figure 10 shows the stress distribution for the CFRP wheel rims at the core and the dowels. Foam near the front and rear parts showed higher stress values owing to the rotational twist of the rim. The stresses could be reduced by increasing the stiffness of centre wall edge. The maximum value of the stress was $0.82 \mathrm{MPa}$ which was well within the yield strength of the core material. The maximum stress of 99.6 MPa was observed on Aluminium tubes placed near mounting points (Fig. 9a). The inclusion of these tubes majorly affected the overall results by reducing the stress levels produced due to clamping force by adding only 0.04 $\mathrm{kg}$ of extra mass to the Rim.

\section{Conclusions}

The finite element analytical results showed that using carbon fibre-reinforced polymer (CFRP) in stackup configuration for wheel rims offered the following advantages:

- Maximum von Mises stress in the CFRP wheel rim was lower by $47 \%$ as compared to metallic wheel rims

- The factor of safety increased to 2.981 for CFRP wheel rims with an increase of $43.4 \%$ with respect to aluminium wheel rims

- The maximum deformation for CFRP wheel rims was higher than that of aluminium wheel rims which could be attributed to the high stiffness and low peak stress observed for CFRP wheel rims.

- The overall wheel rim mass for CFRP was the lowest compared to its metallic counterparts which would mean lower vehicle mass and in turn better handling characteristics of the Formula student car.

While the metallic wheel rims could be machined conveniently using the traditional machining, in the case of CFRP wheel rims, non-conventional machining techniques like abrasive water jet machining and electrical discharge machining are required for producing the desired geometrical features with the necessary tolerances since conventional machining give rise to issues related to polymer composites like delamination, debonding, fibre pull-out and charring of matrix due to high temperatures at the heat affected zones.

Acknowledgements The authors would like to thank the Department of Aeronautical and Automobile Engineering, Manipal Institute of Technology for permitting access to the Computational facility to carry out the modelling and finite element analysis for this work. 
Funding Open access funding provided by Manipal Academy of Higher Education, Manipal. The authors declare that no funding was received for this work.

Conflict of interest The authors declare that they have no known competing financial interests or personal relationships that could have appeared to influence the work reported in this paper.

Open Access This article is licensed under a Creative Commons Attribution 4.0 International License, which permits use, sharing, adaptation, distribution and reproduction in any medium or format, as long as you give appropriate credit to the original author(s) and the source, provide a link to the Creative Commons licence, and indicate if changes were made. The images or other third party material in this article are included in the article's Creative Commons licence, unless indicated otherwise in a credit line to the material. If material is not included in the article's Creative Commons licence and your intended use is not permitted by statutory regulation or exceeds the permitted use, you will need to obtain permission directly from the copyright holder. To view a copy of this licence, visit http://creativecommons. org/licenses/by/4.0/.

\section{References}

1. T. Korkut, E. Armakan, O. Ozaydin et al. Design and comparative strength analysis of wheel rims of a lightweight electric vehicle using al6063 t6 and al5083 aluminium alloys. J. Achiev. Mater. Manuf. Eng. 99(2), 57-63 (2020)

2. S. Choudhary, M. Saifudheen et al., Design and analysis of wheel rim with magnesium alloys (zk60a) by using solidworks and finite element method. Int. Res. J. Autom. Technol. 1(3), 1-16 (2018)

3. A. Doria, L. Taraborrelli, Out-of-plane vibrations and relaxation length of the tyres for single-track vehicles. Proc. Inst. Mech. Eng. Part D J. Autom. Eng. 230(5), 609-622 (2016)

4. V. Tsinias, G. Mavros, Efficient experimental identification of three-dimensional tyre structural properties. Proc. Inst. Mech. Eng. Part D J. Autom. Eng. 233(1), 1-19 (2019)

5. C. Vilar, A. Jesús, F. Antonios, Computational modelling of a solid and deformed automotive rotating wheel in contact with the ground. Proc. Inst. Mech. Eng. Part D J. Autom. Eng. 233(1), 1-12 (2019)

6. A. Strigel, U. Peckelsen, H. Unrau, F. Gauterin, Estimation of feasible ranges of functional tire characteristics based on tire dimension, inflation pressure, and wheel load. Proc. Inst. Mech. Eng. Part D J. Autom. Eng. 233(14), 1-7 (2019)

7. M.P. Saurabh, J.D. Sameer, Modelling and analysis of a motorcycle wheel rim. Int. J. Mech. Eng. Robot. Res. 2(3), 148-156 (2013)

8. D.C. Rohan, Design and analysis of a composite wheel rim. J. Mat. Sci. Mech. Eng. 2(6), 50-56 (2015)

9. C. Shekhar, L. Rao, R. Krishna, Design and structural analysis of car alloy wheel using with various materials. Int. J. Adv. Sci. Res. Eng. Trends 5(7), 114-120 (2020)

10. X. Jiang, X. Hu, H. Liu, D. Ju, Y. Fukushima et al., Study on casting design and analysis of magnesium alloy wheel. Multidiscip. Model. Mater. Struct. 882-894 (2021)

11. V. Karthi, N. Ramanan, J.J.M. Hillary, Design and analysis of alloy wheel rim. Int. J. Innov. Res. Sci. Eng. Technol. 3(2), 71-77 (2014)

12. M.K. Chapman, Development of a composite wheel rim for an FSAE car. UNSW Canberra DFA J. Undergrad. Eng. Res. 4(1), 1-6 (2011)

13. T. Shinde, R. Chavan, P. Savadekar, D. Shinde, N. Jagtap, Failure analysis of a wheel hub of formula student racing car. J. Inst. Eng. (India) Ser. D 102(1), 73-78 (2021)

14. P.G.G. Bhagwat, et al., Design and Analysis of A 10" Carbon Fiber Wheel for a Formula SAE Racecar. PhD Thesis (2017)

15. A. Ressa, Development of a carbon fiber wheel rim. PhD Thesis, (2013)

16. K.R. Salunkhe, S.S. Pimpale, Design, FEM analysis and of alloy wheel rim of a four wheeler. Int. Adv. Res. J. Sci. Eng. Technol. 4(9), 229-235 (2017)

17. H.W. Walther, Development of a Lightweight Laminated Composite Wheel for Formula SAE Race Vehicles. PhD Thesis, University of Kansas (2016)

18. F. Abed, Z. Mehaini, C. Oucif, A. Abdul-Latif, R. Baleh, Quasistatic and dynamic response of GFRP and BFRP bars under compression. Compos. Part C 2, 1-10 (2020)

19. W.F. Milliken, D.L. Milliken et al., Race Car Vehicle Dynamics, vol. 400 (Society of Automotive Engineers, Warrendale, 1995)

20. D. Crolla, Encyclopedia of Automotive Engineering (Wiley, New York, 2015)

21. T.K. Garrett, K. Newton, W. Steeds, Motor Vehicle (ButterworthHeinemann, Oxford, 2000)

Publisher's Note Springer Nature remains neutral with regard to jurisdictional claims in published maps and institutional affiliations. 